\title{
SSynthesis
}

International Scientific Conference of IT and Business-Related Research

\section{PROFITABILNOST BANKARSKOG SEKTORA SRBIJE - PRE I TOKOM KRIZE}

\section{THE PROFITABILITY OF THE SERBIAN BANKING SECTOR - BEFORE AND DURING THE CRISIS}

\author{
Nataša Spahić ${ }^{1}$, Petar Tomić ${ }^{2}$ \\ ${ }^{1}$ Prirodno-matematički fakultet, Univerzitet u Novom Sadu, Novi Sad, Srbija \\ ${ }^{2}$ Erste Bank a.d. Novi Sad, Srbija
}

\begin{abstract}
Apstrakt:
Sa početkom svetske finansijske krize počeo je i privredni pad Srbije, kao i slabljenje životnog standarda stanovništva što je doprinelo do smanjenja kreditne aktivnosti banaka. Ovo smanjenje se značajno odrazilo na finansijske izveštaje banaka kroz smanjenje neto rezultata (iskazani su manji, pa čak i negativni profiti) uzrokovanim uglavnom povećanim troškovima rezervacija za tzv. "loše" kredite. Kako svaki plasman nosi sa sobom određeni rizik, banka mora rezervisati određena sredstva kako bi se zaštitila od rizika. Međutim, rezervacije koštaju i direktno utičuna smanjenje finansijskog rezutltata, a samim tim i na profitabilnost banke iz ugla investitora i akcionara.

$\mathrm{U}$ radu su prezentovani rezultati istraživanja kojim je obuhvaćeno 90\% bankarskog sektora Srbije, tačnije 15 najvećih banaka po bilansnoj sumi. Prati se trend od 2007. do 2013. godine koji obuhvata period pre i tokom krize. Analizom revidiranih finansijskih izveštaja banaka dobijeni su podaci, tj. pokazatelji za merenje profitabilnosti banaka koji ukazuju na stanje pre i tokom krize, kao i na prognoze za predstojeći period.
\end{abstract}

\section{Ključne reči:}

banke, kriza, profitabilnost, finansijski izveštaji.

\section{UVOD}

Današnju privredu, globalno posmatrano karakterišu opšta ekonomska kriza, nedostatak novca, urušena industrija, nizak BDP, visoka nezaposlenost, visoka stopa inflacije i nizak životni standard. Banke su na vrhuncu kreditiranja, preduzećima su odobreni maksimalni iznosi kredita, ali se ona, i sa tom dodatnom likvidnošću, teško bore da ostvare dodatne prihode kako bi vratila pozajmljena sredstva. Rashodi iz budžeta su sve veći, a zaposlenima u javnom sektoru su smanjene plate. Generalno, životni standard opada i na niskom je nivou što ima dvostruki uticaj: građani su sve manje u mogućnosti da konzumiraju neka određena dobra što utiče negativno (u finansijskom smislu) na proizvođače i prodavce tih dobara, dok sa druge strane građanima trebaju dodatna novčana sredstva kako bi mogli da podmire osnovne životne potrebe. U oba slučaja banka se javlja kao izvor sredstava: preduzećima plasira kredite kako bi uvećala i unapredila proizvodnju, dok građanima odobrava zajmove kako bi mogli da kupuju te proizvode. Sa dolaskom krize, privrednim padom i padom životnog standarda dolazi do

\section{Abstract:}

Economic downturn of Serbia was triggered by the outbreak of the global financial crisis, and the weakening of the population's standard of living, which led to the decreased lending activity of the banks. This decrease had a significant impact on the bank's financial statements through decrease of the net results (they are lower, and even negative in some cases), which are mainly driven by the increased risk of costs for non-performing loans (NPL). As every placement carries certain level of risk, the banks need to reserve the specified amount to protect themselves against risk. On the other hand, investors and shareholders believe that such funds are costly, and have a direct negative impact on the financial results, and therefore, on the lower profitability of banks.

The paper presents the results of the research, which encompasses $90 \%$ of the Serbian banking sector, i.e. 15 largest banks according to total assets. The trend from 2007 till 2013 is observed, which includes the period before and during the crisis. The data is collected by means of the analysis of the audited banking financial statements, i.e. bank profitability ratios showing the situation before and during the crisis, and the forecasts for the upcoming period.

\section{Key words:}

banks, crisis, profitability, financial statements.

poteškoća u otplati kredita, kako od strane preduzeća, tako i od strane građana. Upravo iz tih razloga banka rezerviše određena novčana sredstva kako bi se zaštitila od kreditnog rizika ${ }^{1}$ (Basel Committee on Banking Supervision, 2013). Ta sredstva koštaju banku, tačnije njene akcionare i investitore, jer se ta sredstva za rezervacije crpe direktno iz kapitala banke i samim tim utiču na profit banke.

Autori ovog istraživanja, primenom metodologije revizije banaka za bilansne pozicije stanja i troškova rezervacija za plasmane, ukupne aktive i kapitala, fokus stavljaju na najveće banke u Srbiji, tačnije na 15 najvećih banaka, pri čemu je kao kriterijum veličine banke uzet iznos ukupne bilansne sume banke. Tih 15 banaka autori posmatraju kao celinu na kojoj će i celokupna analiza biti bazirana. Ukupna bilansna suma 15 najvećih banaka iznosi $90 \%$ od celokupnog bankarskog sektora Srbije (Narodna banka Srbije, 2014). Bazu podataka čine javno obelodanjeni revizorski izveštaji banaka, kao i izveštaji o bankarskom sektoru sačinjeni od strane Narodne banke Srbije.

1 Kreditni rizik je rizik spremnosti i mogućnosti dužnika da izmiri obaveze prema zajmodavcu (najčešće banci). 
Cilj istraživanja je da se uporedi bankarsko poslovanje pre krize i u toku krize, odnosno da se ukaže na značaj upravljanja kreditnim rizikom i njegov uticaj na finansijski rezultat banke. $\mathrm{U}$ radu su kao mere profitabilnosti korišćena racija ROE (return on equity), ROA (return on assets) i C/I (cost to income).

\section{PREGLED NAJVEĆIH BANAKA U SRBIJI}

Srpske banke rangirane su po kriterijumu veličine bilansne sume (po ukupnoj aktivi izraženoj u milijardama dinara). Istraživanjem je obuhvaćeno 15 najvećih banaka u Srbiji sa stanjem na dan 31.12.2013. godine. Na grafiku 1 predstavljeno je rangiranje ovih banaka sa prikazanim učešćem u ukupnoj aktivi celokupnog bankarskog sektora Srbije, tj. sa njihov tržišnim učešćima (Narodna banka Srbije, 2014).

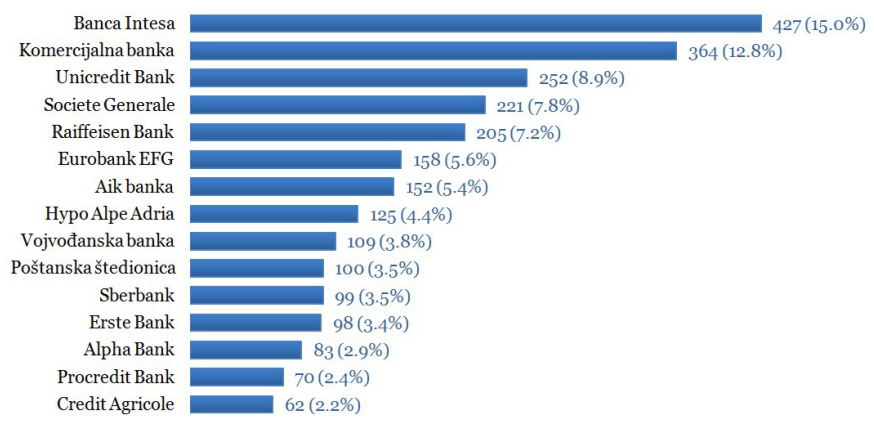

Grafikon 1. Pregled 15 najvećih banaka, milijardi dinara (\%učešća)

Istraživanjem je obuhvaćeno 90\% ukupne bilansne aktive svih srpskih banaka, odnosno 90\% srpskog bankarskog sektora, što prema korišćenoj metodologiji revizije predstavalja adekvatan uzorak za izvođenje relevantnih zaključaka.

\section{MERE PROFITABILNOST}

Uzimajući u obzir da se veoma malo srpskih banaka kotira na berzi, iz analize će biti izuzeta racija poput EPS (earnings per share - zarada po akciji), P/B (price-to-book - odnos tržišne cene akcije i knjigovodstvene vrednosti) i slična, inače veoma rasprostranjena racija za merenje profitabilnosti. Autori u radu su se opredelili za ona racija koja se lako izračunavaju na osnovu bilansa stanja i bilasna uspeha, a koja daju osnovnu sliku o profitabilnosti poslovanja (Bikker \& Boss, 2013).

Pozitivan neto rezultat (profit) ne mora nužno da znači da je banka profitabilna. Ukoliko investitor može da zaradi više novca ulažući ga negde drugde, npr. u nerizične hartije od vrednosti, onda je jasno da taj profit mora da bude, u relativnom smislu, iznad neke vrednosti, koja se u investicionom svetu naziva benčmark (od engleske reči benchmark).

Jedan od koriščenih racija u radu je ROE (return on equity - prinos na kapital) koji stavlja u odnos neto profit i prosečan kapital u toku poslovne godine. Predstavlja iznos prinosa koji ostvaruje investitor/akcionar ulažući u kapital banke. Niske vrednosti ovog racija ukazuju na veoma nisku zaradu (Gilbert \& Wheelock, 2007).

Drugi korišćeni racio je ROA (return on assets - prinos na aktivu) koji stavlja u odnos neto profit i prosečnu ukupnu aktivu u toku poslovne godine i predstavlja koliki prinos ostvaruju bančina sredstva, tj. koliko banka zarađuje na svojoj imovini.
Analizom bilansa banaka lako se može utvrditi da plasmani (krediti stanovništvu i privredi, hartije od vrednosti i ostali) čine preko $85 \%$ ukupne bilansne sume što nas dovodi do zaključka da ROA predstavlja adekvatan pokazatelj.

Treći racio, C/I (cost to income - odnos troškova i prihoda) stavlja u odnos operativne troškove i operativne prihode. Operativne troškove čine svi oni troškovi koji su neophodni kako bi banka mogla da obavlja svoju funkciju (troškovi plata zaposlenih, amortizacija osnovnih sredstava kao i ostali operativni troškovi), dok operativne prihode čine prihodi nastali bankarskim aktivnostima (neto kamatni prihod, neto prihod od naknada, neto rezultat trgovanja kao i ostali poslovni prihodi). Ono je što je bitno napomenuti, a to je da trošak ispravki ne ulazi u operativne troškove, i stoga ne čini deo C/I racija, što će nam dati jasniju sliku o tome ko više utiče na poslovanje banke.

\section{ANALIZA BILANSNIH POZICIJA}

Analizirajući trend ukupne bilansne sume u periodu od 31.03.2007. do 31.12.2013. godine uočava se da su banke uvećale svoju aktivu više nego duplo (rast od $102 \%$ posmatrajući rast u K4 2013 u odnosu na K4 2007²). Prosečan rast aktive je bio oko $13 \%$ posmatrajućirespektivno, što se vidi na grafiku 2 (iznosi su u milijardama dinara). Ovi rezultati ukazuju da su banke uvećavale plasmane iz godine u godinu, s obzirom na činjenicu da plasmani čine preko $80 \%$ aktive banaka.

Posmatrajući kretanje kapitala u istom periodu takođe vidimo da je kapital sektora udvostručen (porastao za 120\% u poslednjih 6 godina, sa prosečnim rastom od 15\% godišnje), što je prikazano na grafiku 3 (iznosi su u milijardama dinara). Zanimljivo je da je prosečno stanje kapitala (crvena linija na grafiku) imalo veliki skok u 2008. godini u odnosu na 2007. godinu (38\%), u vreme kada svetska finansijska kriza još uvek nije došla na prostore Srbije. Navedno ukazuje da su dobici banaka bili pozitivni, što automatski uvećava kapital. Međutim, u narednim godinama rast kapitala usporava (prosečan rast iznosi $10 \%$ godišnje) što implicaraznatno niže profite banaka, a u nekim slučajevima i gubitke (gubici utiču na smanjenje kapitala). Jedan od značajnijih razloga za to je povećanje potrošnje banaka na rezervacije za „loše” plasmane, koje bankama predstavljaju trošak u bilansu uspeha, a samim tim i umanjuju dobitak (ili ga pretvaraju u gubitak) i kapital. Razlog zbog kojeg banke povećavaju rezervisanja jeste jak uticaj svetske krize koja pogoršava celokupno ekonomsko stanje u zemlji i povećalo kreditni rizik bankama (Basel Committee on Banking Supervision, 2006).

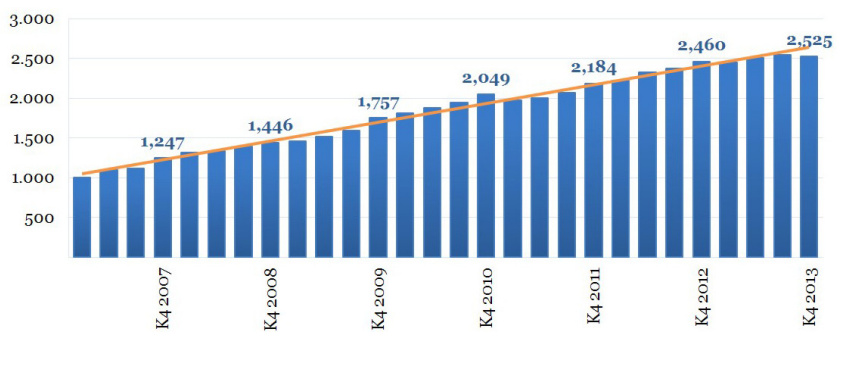

Grafikon 2. Trend ukupne aktive za period od 31.03.2007. do 31.12.2013. godine

$2 \mathrm{~K}$ - oznaka za kvartal u godini. 


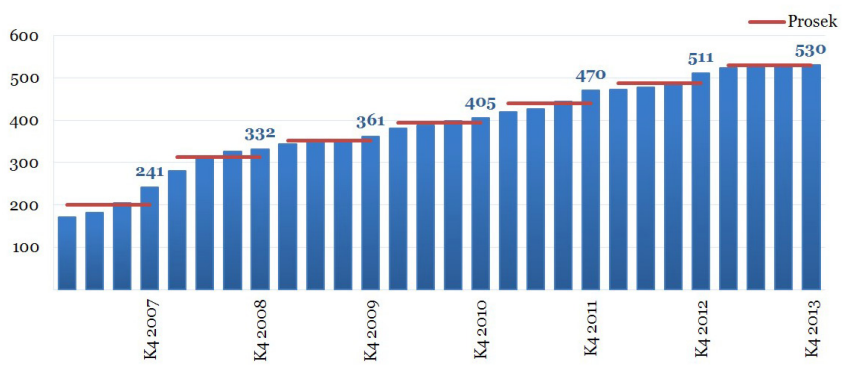

Grafikon 3. Trend kapitala u periodu od 31.03.2007. do 31.12.2013. godine

Da bi se uočila veza između troška rezervacija i finansijskog rezultata, neophodno je analizirati njihov trend i odrediti koeficijent korelacije ${ }^{3}$, koji određuje jačinu veze. Trend analiza je predstavljena na grafiku 4 (iznosi su u milijardama dinara). Analizom kretanja predmetnih varijabli dolazi se do rezultata koji pokazuje da je koeficijent korelacije $-0,76$ što predstavlja jaku negativnu linearnu vezu. Uočava se da se trošak ispravki povećava prosečno oko $20 \%$ na godišnjem nivou (počevši od 2008. godine) dok se sa druge strane neto rezultat smanjuje u proseku od oko 5\% što je direktno uzrokovano rastom troška.
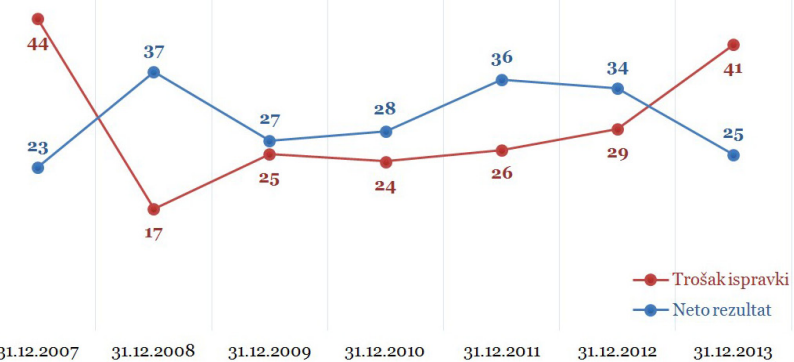

Grafikon 4. Analiza troška rezervacija i profita za period od 31.12.2007. do 31.12.2013. godine

Predstavljeni rezultati zaista ukazuju na jak uticaj upravljanja kreditnim rizikom na finansijski rezultat banaka. Plasiranjem sredstava banke zarađuju novac, međutim kako svaki plasman sa sobom nosi rizik banke se moraju zaštiti, što za banke predstavlja trošak čak i do iznosa preostalog duga, što u praksi mogu biti veoma veliki iznosi.

\section{ANALIZA PROFITABILNOSTI}

Gore analizirana kretanja bilansnih pozicija su nagovestila da bankarski sektor iz godine u godinu sve teže ostvaruje profite, a kao uzrok tome je svakako ekonomska kriza koja potrese kako privredu tako i stanovništvo. Stavljajući u odnose pojedine stavke bilansa stanja i bilansa uspeha banaka dobijamo racija koja su nam značajna za praćenje profitabilnosti bankarskog sektora Srbije.

3 Brojna vrednost (koeficijent) koja predstavlja u kojoj meri su dve varijable međusobno povezane. Vrednost može biti u rasponu od -1 (savršena negativna linearna veza) do 1 (savršena pozitivna linearna veza). Za vrednost 0 zaključujemo da varijable nisu linearno povezane.
Među najznačajnijim racijima je svakako ROE koji predstavlja koliko zarađuju investitori na svaki uloženi dinar. Dobija se kao odnos neto rezultata i prosešnog kapitala za posmatranu poslovnu godinu. Povećanjem profita povećava se ROE, dok se smanjenjem dogodi obrnuto. Posmatrajući kapital važno je istaći da profit uvećava kapital, a povećani kapital umanjuje ROE jer se nalazi u imeniocu razlomka. Ukoliko je rast profita veći od rasta kapitala (govoreći relativno) onda će i ROE rasti.

Iz prethodno predstavljenih rezultata uočava se da rezultat opada prosečno $5 \%$ godišnje, dok kapital raste oko $10 \%$ godišnje, za posmatrani period od 2008. do 2013. godine što predstavlja dovoljnu osnovu za zakjučak kojim se tvrdi da ROE bankarskog sektora Srbije opada iz godine u godinu, kako je i vidljivo na grafiku 5:

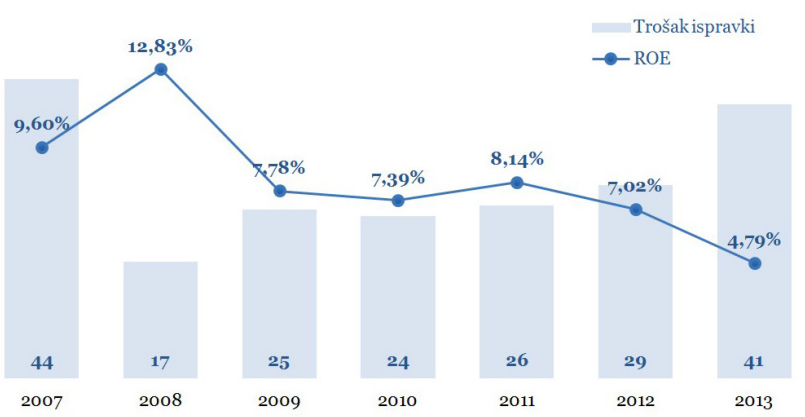

Grafikon 5. Trend kretanja ROE u periodu od 2007. do 2013. godine

Iz priloženog trenda može se uočiti da trošak ispravki raste tokom perioda krize, što umanjuje neto rezultat banaka, pa samim tim i kapital. Međutim, da bi održale likvidnost na regulatornom nivou ${ }^{4}$ (Narodna banka Srbije, 2012), banke ne mogu uvek trošiti sredstva iz kapitala za zaštitu od rizika, jer će ga vremenom istrošiti do mere da pokazatelj adekvatnosti kapitala padne ispod minimalnih $12 \%$. Shodno tome, bankama je neophodna dokapitalizacija kako bi održale likvidnost na zahtevanom nivou. Međutim, dokapitalizacijom banke urušavaju svoju profitabilnost iz razloga što beleže uvećan kapital, ali i veće troškove rezervacija i manju profit (ili čak i gubitak), što se jasno očitava kroz. formulu za ROE (manji brojilac i veći imenilac) i jasno govore u tome da ROE mora opadati.

Nakon rasta u 2008. godini, sa $9,60 \%$ na $12,83 \%$, ROE pokazatelj je u skoro konstantnom padu (u proseku za oko $2 \%$ na godišnjem nivou, gledajući apsolutno) u periodu od 2008. do 2013. godine, da bi 2013. godine dospeo na veoma niskih $4,79 \%$. Uzimajući u obzir da su na aukciji državnih hartija od vrednosti Republike Srbije na dan 30.12.2013. godine emitovane nerizične hartije sa rokom dospeća od 12 meseci i prinosom od $8,89 \%$, jasan je zaključak da je ROE bankarskog sektora nizak, tj. da je ulaganje u banke neprofitabilno, iz ugla investitora. Investitori su mogli zaraditi sigurnih $8,89 \%$ na nerizične obveznice države Srbije, ali su ipak odlučili da rizikuju i zaradili su svega $4,79 \%$ uloženog novca. Razlika od 4,10 procentnih poena predstavlja tzv. oportunitetni trošak ${ }^{5}$ za investitore.

4 Banke su dužne po Odluci o adekvatnosti kapitala da održavaju nivo pokazatelja adekvatnosti kapitala na minimumu od $12 \%$. Ova tema jeste usko povezana za upravljanjem kreditnim rizikom ali se više tiče likvidnosti, pa stoga autori ne analiziraju detaljnije uticaj na pokazatelj adekvatnosti kapitala.

5 Oportunitetni trošak predstavlja trošak onoga čega treba da se odreknete u cilju dobijanja nekog drugog dobra 
Sledeći racio relevantan za analizu profitabilnosti je $R O A$, koji predstavlja koliko zarađuje bančina aktiva, tj. koliko su bančina sredstva profitabilna. Dobija se kao odnos neto rezultata i prosečne aktive za posmatranu poslovnu godinu. Povećanjem profita povećava se ROA. Što se tiče aktive, profit uvećava kapital, koji uvećava ukupnu pasivu, a kako mora da važi osnovna jednačina računovodstva, raste i aktiva, koja svojim rastom umanjuje ROA jer se nalazi u imeniocu razlomka. Ukoliko je rast profita veći od rasta aktive (govoreći relativno) onda će i ROA rasti.

$\mathrm{U}$ ranije prezentovanim analizama, uočeno je da profiti banaka rastu za oko 5\% godišnje, u proseku, dok aktiva raste brže (prosečno oko 13\% godišnje) za posmatrani period od 2008. do 2013. godine. Iz definice ROA jasan je efekat, a to je da ROA opada iz godine u godinu, što je i prikazano na grafiku 6:

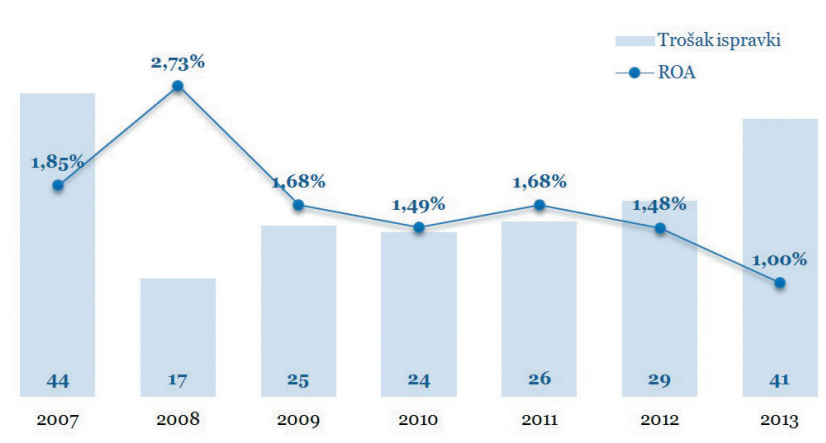

Grafikon 6. Trend kretanja ROA u periodu od 2007. do 2013. godine

Plasmani banaka su rasli, kreditiranje su uvećavalo, što je imalo za uticaj porast aktive. Na pitanje zašto i profit nije pratio rast plasiranih kredita odgovor je: ekonomska kriza, i pad kvaliteta bankarske aktive, tj. povećan nivo loših plasmana i sve većeg kašnjenja u otplati istih. ROA prikazuje koliko banka zaradi (procentualno) za svaki plasirani dinar. Ukoliko se kasni sa otplatom, banka ima povećane troškove rezervacija za loše kredite i manje priliva od kamata što negativno utiče na finansijski rezultat i samim tim na zaradu banke po jedinici kredita, tj. manji ROE.

Kao što je bio slučaj i kod ROE, ROA beleži rast u 2008. godini, dok u nadolazećim godinama pada za oko $0,3 \%$ u proseku na godišnjem nivou, posmatrajući apsolutno. S obzirom da cena kredita banaka sadrži u sebi i tržne stope (dinarski krediti su uglavnom vezani za Belibor stopu ${ }^{6}$, dok su krediti u evrima vezani za Euribor stopu ${ }^{7}$ ) koje su veće od prikazanih ROA pokazatelja jasno je još jednom da je bankasrki sektor neprofitabilan (primera radi, šestomesečni Belibor na dan 31.12.2013. godine je iznosio 9,15\% (Narodna banka Srbije, 2013,) što nam govori da su banke zarađivale manje nego što su trebale, jer je tih 9,15\% bilo uključeno u cenu plasiranog kredita).

Poslednji deo analize posvećen je trendu C/I racija, koji prikazuje odnos operativnih troškova i operativnih prihoda, koliko banka operativno novca ${ }^{8}$ potroši da bi zaradila prihode

6 BELIBOR je referentna kamatna stopa po kojoj vodeće srpske banke pozajmljuju novac - dinare jedna drugoj.

7 EURIBOR, ili evropska međubankarska stopa (Euro Interbank Offered Rate), predstavlja dnevnu referentnu kamatnu stopu po kojoj 57 prvoklasnih evropskih banaka jedna drugoj pozajmljuju novac na međubankarskom tržištu.

8 Operativni novac banke je novac koji banka potroši na plate zaposlenih, na usluge i servise za obavljanje novčanih transakcija, na amortizaciju bankmoata i POS aparata i sl. iz svog poslovanja (na primer, prihode od kamata i naknada, kursnih razlika, ulaganja u hartije od vrednosti). Ovaj racio ne obuhvata troškove rizika, pa stoga prikazuje kako je banka operativno poslovala.

Trend operativnih prihoda i rashoda, kao C/I racio prikazan je na grafiku 7:

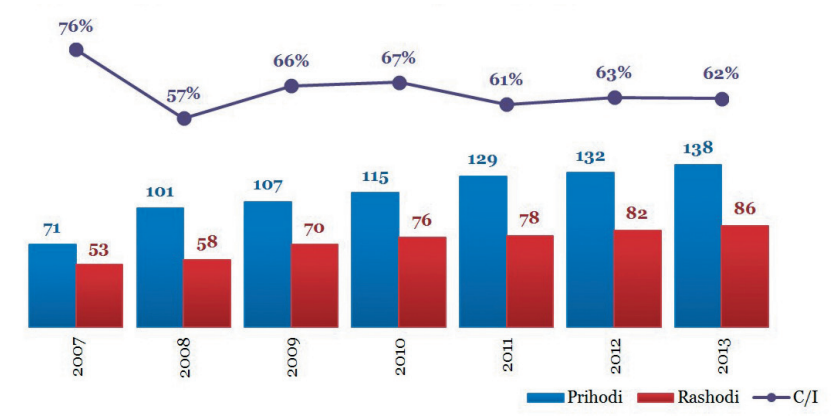

Grafikon 7. Trend kretanja operativnih prihoda, rashoda i C/I u periodu od 2007. do 2013. godine

Analizom prihoda i rashoda uočava se da je trend rastući, a kao u prilog tome ide i činjenica da je bilansna suma rasla na godišnjem nivou. Povećani prihodi neizostavno povlače sa sobom i rastuće rashode. Prihodi su imali veliki skok u 2008. godini, od čak $43 \%$, dok se u narednim godinama taj rast drastično smanjuje i iznosi svega oko $6 \%$ prosečno na godišnjem nivou, čiji uzorčnik je definitno ekonomska kriza. Posmatrajući ceo period, prihodi su rasli oko $13 \%$ godišnje u proseku. Sa druge strane, rashodi su manje varijabilni i imaju stabilan rast od oko prosečnih $8 \%$ tokom posmatranog perioda, sem porasta u 2009. godini od $22 \%$. Prihodi rastu brže od rashoda, što bi u matematičkom smislu značilo da brojilac raste brže od imenioca što ukazuje da C/I racio opada. Ovaj podatak pokazuje rast rashoda ne prati linearno rast prihoda, a to ne znači ništa drugo nego da su se banke trudile da štede i da operativne troškove svode na minimalne nivoe.

\section{ZAKLJUČAK}

Kraj ekonomske krize u Srbiji se još uvek ne nazire, iako se prema nekim prognozama očekuje privredni rast u 2016. godini. Do tada će banke biti i dalje suočene sa problemom pada profitabilnosti i pitanjem kako da uvećaju prihode bez preterano povećanih rashoda, ili kako da smanje troškove, a da produktivnost bude na istom ili višem nivou. Sa druge strane, niska profitabilnost povećava sumnju investitorima i smanjuje njihovu želju za dalje investicije što može ima negativnih efekata poput povlačenja poslovanja iz Srbije, što bi opet imalo negativnog uticaja i na ekonomski rast, jer bi u tom slučaju došlo do odliva stranog kapitala.

Prezentovana analiza ima za cilj da pokaže da kriza utiče i na banke, a ne samo na nefinansijska preduzeća. Visok je nivo kreditnog rizika, stopa nenaplativih kredita je na kraju 2013. godine iznosila $21,4 \%$ od ukupno plasiranih (Narodna banka Srbije, 2014), prihodi banaka su ograničeni. Sa druge strane, banke se trude da operativne troškove drže na minimalnom nivou, ali ono što ih zaista košta to je upravljanje kreditnim rizikom i troškovi rezervisanja za nevraćene kredite koji prazne kapital i guraju profitabilnost banaka na dole.

Analiza je pokazala da racija ROE i ROA padaju usled sve nižih profita koji nisu povećani regularnim operativnim troš- 
kovima. To se uočava iz analize C/I racija koja je prikazala da banka povećava svoje operativne prihode više nego rashode. Problem je u povećanim troškovima rizika koji iz godine u godinu rastu i opterećuju kapital. Ti troškovi će rasti dokle god se ekonomija ne oporavi, i preduzeća počnu bolje da posluju, a samim tim i redovnije da vraćaju kredite.

\section{LITERATURA}

Basel Committee on Banking Supervision. (2006). Studies on credit risk concentration: an overview of the issues and a synopsis of the results from the Research Task Force project (Working Papers No. 15). Preuzeto 15. Novembra, 2014. sa http://www.bis.org/publ/bcbs_wp15.pdf

Basel Committee on Banking Supervision. (2013). The non-internal model method for capitalizing counterparty credit risk exposures - consultative document. Preuzeto 15. Novembra, 2014. sa http://www.bis.org/publ/bcbs254.pdf
Bikker, J. A., \& Bos, J.W.B. (2008).Bank performance: A theoretical and empirical framework for the analysis of profitability, competition and efficiency. New York: Routledge.

Gilbert, R.A., \& Wheelock, D.C. (2007). Measuring Commercial Bank Profitability: Proceed with Caution. Sv. Luis, SAD: Federal Reserve Bank of St. Louis Review

Narodna banka Srbije. (2014). Bankarski sektor u Srbiji - izveštaj za IV tromesečje 2013.; 2012.; 2011.; 2010.; 2009.; 2008. i 2007. Preuzeto 20. Novembra, 2014. sa http://www.nbs.rs/ internet/latinica/55/55_4/

Narodna banka Srbije \& Službeni glasnik RS, br. 46/2011, 6/2013, $51 / 2014$. Odluka o adekvatnosti kapitala banke. Preuzeto 20. Novembra, 2014. sa http://www.nbs.rs/export/sites/ default/internet/latinica/20/kpb/adekvatnost_kapitala.pdf

Narodna banka Srbije \& Službeni glasnik RS, br. 123/2012. Odluka o upravljanju rizicima banke. Preuzeto 12. Novembra, 2014. sa http://www.nbs.rs/export/sites/default/internet/ latinica/20/kpb/upravljanje_rizicima.pdf 